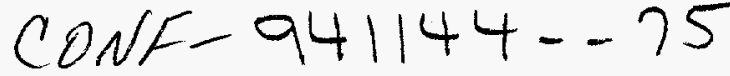

\title{
THE EFFECTS OF PROCESSING VARIABLES ON REACTION SYNTHESIS OF Fe-AI ALLOYS
}

D. L. JOSLIN, D. S. EASTON, C. T. LIU, AND S. A. DAVID

Metals and Ceramics Division, Oak Ridge National Laboratory, Oak Ridge, TN 37831-6115

\begin{abstract}
The effects of alloy composition and reaction atmosphere on reaction synthesis of binary FeAl alloys were studied. Reactions were observed in an open (air) furnace, under static vacuum (in an evacuated quartz tube) and in a dynamic vacuum furnace. High-speed videotapes of reaction syntheses of compacts formed from $45-\mu \mathrm{m} \mathrm{Fe}$ and $10-\mu \mathrm{m} \mathrm{Al}$ powders reacted in air and under static vacuum revealed that an unusual "two-stage" reaction exists in this system under these conditions. The first stage of the two-stage reaction lasts several seconds and starts at around $650^{\circ} \mathrm{C}$. The second stage begins at about $900^{\circ} \mathrm{C}$, reaching temperatures between 1250 and $1350^{\circ} \mathrm{C}$. The progress of the reaction to the second stage is sensitive to the alloy composition and reaction environment. The reaction behavior is explained in terms of thermodynamics and heat transfer, which control the delicate balance between heat accumulation and heat loss during reaction synthesis.
\end{abstract}

\section{INTRODUCTION}

The iron aluminides $\mathrm{FeAl}$ and $\mathrm{Fe}_{3} \mathrm{Al}$ show promise for a broad range of applications. They have lower densities and good high-temperature properties compared to many structural alloys currently in use. ${ }^{1}$ However, their use as engineering materials has been restricted since they exhibit brittle fracture and low ductility at ambient temperatures, which limits their fabricability. 2, 3 Reaction synthesis of these alloys has received particular attention as a solution to the problem of fabrication ${ }^{3-7}$ since the process has the advantages of near-net shaping, energy savings, and relatively low cost. 8,9 However, reasonable densification ( $>97 \%$ of theoretical) of reaction-synthesized iron and nickel aluminides has not been achieved except with the application of pressure during the reaction. $5-8$

Most of the earlier studies involving $\mathrm{Fe}-\mathrm{Al}$ alloys ${ }^{4-7}$ were conducted under conditions that prohibited direct observation of the synthesis reaction. Also, the reaction furnaces were taken to temperatures on the order of $1000^{\circ} \mathrm{C}$ for 1 hour or more, where some homogenization might occur. The present investigation was initially undertaken to elucidate the details of reactions in an $\mathrm{Fe}-35.8$ at.\% Al system, in which two separate reaction "stages" were observed to occur under certain experimental conditions. Preliminary results from this study have been published elsewhere. 10

\section{EXPERIMENTAL}

Elemental iron and aluminum powders were combined in the following compositions: 25,30 , $35.8,45$, and 54 at.\% Al, using $45-\mu \mathrm{m}$ iron with $10-\mu \mathrm{m}$ aluminum powders, which were then mixed together by ball milling for $24 \mathrm{~h}$. Cylindrical green compacts either 12.7 or $25.4 \mathrm{~mm}$ in diameter and about $6.7 \mathrm{~mm}$ thick were fabricated in a hydraulic press. The green densities of the compacts varied between 68 and $78 \%$ of theoretical.

Reactions were observed in an open furnace (in air), under dynamic vacuum (in a vacuum furnace at $1.33 \times 10^{-4} \mathrm{~Pa}$ ) and under static vacuum (in a quartz tube evacuated to $1.33 \times 10^{-4} \mathrm{~Pa}$ ). In all cases, the specimens were placed in the furnace at $450^{\circ} \mathrm{C}$. The furnace controller was then set to $750^{\circ} \mathrm{C}$, allowing the sample temperature to rise to the initiation temperature for the synthesis reaction. For the syntheses in air and under static vacuum, the sample temperature was monitored by infrared pyrometry, using a dual sensor pyrometer system (manufactured by Ircon, 


\section{DISCLAIMER}

This report was prepared as an account of work sponsored by an agency of the United States Government. Neither the United States Government nor any agency thereof, nor any of their employees, makes any warranty, express or implied, or assumes any legal liability or responsibility for the accuracy, completeness, or usefulness of any information, apparatus, product, or process disclosed, or represents that its use would not infringe privately owned rights. Reference herein to any specific commercial product, process, or service by trade name, trademark, manufactuier, or otherwise does not necessarily constitute or imply its endorsement, recommendation, or favoring by the United States Government or any agency thereof. The views and opinions of authors expressed herein do not necessarily state or reflect those of the United States Government or any agency thereof. 


\section{DISCLAIMER}

Portions of this document may be illegible in electronic image products. Images are produced from the best available original document. 
Inc., Niles, IL). Temperatures between 450 and $760^{\circ} \mathrm{C}$ were monitored by a standard infrared pyrometer; temperatures above $760^{\circ} \mathrm{C}$ were monitored by a two-color infrared pyrometer. Selected reactions were taped using high speed video equipment operating at 500 or 1000 frames/s. Quenching experiments were performed on encapsulated 35.8 at.\% Al specimens; the samples were quenched in water soon after the first stage of the reaction passed through the whole sample. Either electron microprobe analysis or X-ray diffraction analysis was performed to determine the products of each reaction stage.

\section{RESULTS AND DISCUSSION}

\section{$\underline{\text { Reaction Behavior }}$}

Pyrometry data from various reactions are plotted in Figs. 1-3. Since data acquisition began well before the initiation of the synthesis reaction and the length of time before initiation differed from sample to sample, it was necessary to shift the curves in these figures along the time axis so that the durations of the reactions could be easily compared. The differences in ignition temperature are probably due to the fact that the emissivities of the sets of compacts are a little different from 0.75 , the value which was used for pyrometry in the temperature range $450-700^{\circ} \mathrm{C}$.

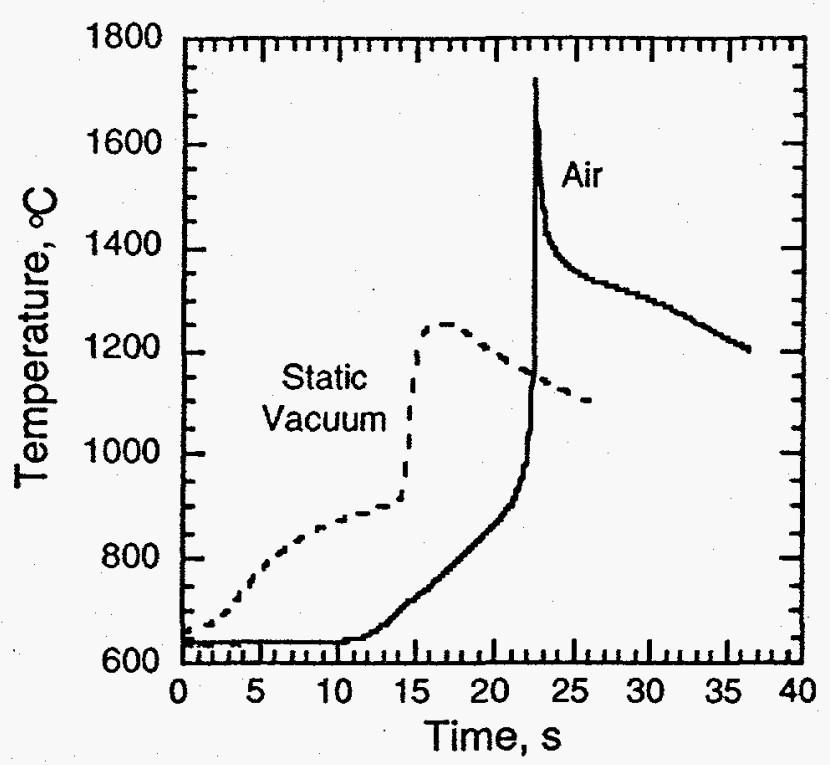

Fig. 1. Pyrometry data from reactions of Fe35.8 at. \% Al compacts reacted in air and under static vacuum.

Pyrometry data from reactions of 24.5 $\mathrm{mm}$ dia. Fe-35.8 at.\% $\mathrm{Al}$ compacts in air and under static vacuum are compared in Fig. 1. Pyrometry measurements performed on these and several other samples show that the peak temperature is apparently higher for reactions in air than for reactions under static vacuum. The differences in peak temperature measured between the two atmospheres are probably due to differences in sample heating rate under static vacuum and in air, and the availability of oxygen during the reaction in air. Slower heating rates associated with the static vacuum allow dissipation of the heat of reaction; therefore less heat is accumulated to trigger and complete the combustion reaction. The oxygen available during the reactions in air allows further oxidation of the powder particles, as evidenced by the weight gains measured after such reactions. Since the iron particles presumably oxidize during heating, the thermite reactions (reactions 1-3,11 Table 1) play a larger role in air synthesis. All of these reactions are more highly exothermic than any of the reactions forming iron aluminides from the elemental powders (reactions $4-74,12$ ). The fact that the measured peak temperatures achieved in air are generally higher than predicted by thermodynamic analysis supports this idea, as do the electron microprobe and x-ray diffraction results listed in Table 2 . The results from the surface of a 35.8 at.\% Al compact reacted in air show that the sample contains $\mathrm{FeAl}$ and $\mathrm{Al}_{2} \mathrm{O}_{3}$ in both the surface layer and in the interior.

A major difference in reaction behavior between the two atmospheres is that, under static vacuum, the first reaction stage passes completely through the compact before the second stage begins, whereas in air it does not. From the curve for the compact reacted under static vacuum, the first reaction stage lingers for about $14 \mathrm{~s}$ at temperatures between 800 and $900^{\circ} \mathrm{C}$, and then the second stage begins, finally reaching a maximum temperature between 1250 and $1350^{\circ} \mathrm{C}$, with the entire reaction occurring in about $16 \mathrm{~s}$. In air, the duration of the first-stage reaction is 
around $7 \mathrm{~s}$; the total reaction time is about $8 \mathrm{~s}$. These differences arise from the heat balance of the systems in the two environments as discussed above.

The temperature profiles for the first-stage reaction under air and static vacuum is also notably different. The reaction rate for the first-stage reaction in air is very nearly constant. In contrast, the reaction rate for the first-stage reaction under static vacuum undergoes several changes. Such behavior has been noted in numerous ceramic systems, 13 , e.g. and in other intermetallic systems. ${ }^{14-16}$ Those experiments helped shed light on the reaction behavior observed in this study and bolster the arguments made here. For example, the differential thermal analysis (DTA) data of Rabin and Wright ${ }^{4}$ taken on $\mathrm{Fe}-28$ at. \% $\mathrm{Al}$ shows a lower-temperature exotherm $\left(625^{\circ} \mathrm{C}\right)$ which they attribute to solid-

Table 1. Possible reactions during synthesis of $\mathrm{Fe}-\mathrm{Al}$ powders.

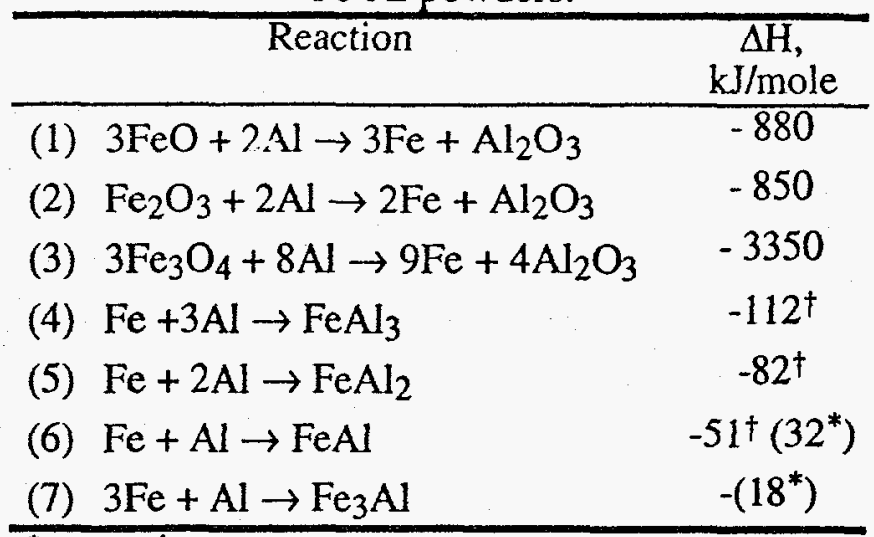
state compound formation preceding initiation of the synthesis reaction. The change in the reaction rate during the first-stage reaction observed in the 35.8 at.\% Al sample reacted under static vacuum (Fig. 1) may be related to the formation of one or more high-melting-point compounds that act as diffusion barriers, impeding the progress of the first-stage reaction to the second stage. One explanation for the constant reaction rate during the first-stage reaction in air is that the additional heat that is generated due to the thermite reactions ${ }^{11}$ which occur in the presence of air raises the temperature of the sample quickly, and the diffusion barriers are thus overcome.

Pyrometry data from reactions of $24.5 \mathrm{~mm}$ dia. compacts formed from various iron-

Table 2. Electron microprobe analysis $\left(^{*}\right)$ and $\mathrm{X}$-ray diffraction results. All samples were $25.4 \mathrm{~mm}$ diameter.

\begin{tabular}{|c|c|c|}
\hline $\begin{array}{l}\text { Reaction } \\
\text { Conditions }\end{array}$ & $\begin{array}{l}\text { Compo- } \\
\text { sition } \\
\text { at.\% Al }\end{array}$ & $\begin{array}{l}\text { Constituents } \\
\text { Present }\end{array}$ \\
\hline air & 35.8 & $\begin{array}{l}\text { Surface: } \mathrm{FeAl}+\text { trace } \mathrm{Al}_{2} \mathrm{O}_{3} \\
\text { FeAl: } \mathrm{Al}_{2} \mathrm{O}_{3} \text { intensity ratio }=0.0107 \\
\text { Center: } \mathrm{FeAl}^{+} \text {trace } \mathrm{Al}_{2} \mathrm{O}_{3} \\
\text { FeAl: } \mathrm{Al}_{2} \mathrm{O}_{3} \text { intensity ratio }=0.0290\end{array}$ \\
\hline
\end{tabular}

static $\quad 35,8^{*} \quad \mathrm{Fe}$ and $\mathrm{FeAl}_{3}$ (major);

vacuum $\quad 95$ at. $\% \mathrm{Al}$ (minor)

$35.8^{\dagger} \mathrm{FeAl}$ (major) $\mathrm{Fe}_{3} \mathrm{Al}$

30* $\quad \mathrm{Fe}$ and $\mathrm{FeAl}_{3}$

dynamic $\quad 35.8$ Surface: $\mathrm{FeAl}+\mathrm{Al}_{2} \mathrm{O}_{3}$

vacuum $\quad \mathrm{FeAl}: \mathrm{Al}_{2} \mathrm{O}_{3}$ intensity ratio $=0.0051$ Center: FeAl

${ }^{*}$ quenched after $1^{\text {st }}$ stage ${ }^{\dagger}$ reacted through $2^{\text {nd }}$ stage aluminum compositions, and conducted under static vacuum are shown in Fig. 2. The samples with compositions $\leq 30$ at. $\% \mathrm{Al}$ undergo only a single "lowtemperature" (first-stage) reaction that initiates at around $700^{\circ} \mathrm{C}$, and reaches a maximum temperature of about $870^{\circ} \mathrm{C}$. The aluminum content of these compacts is probably too low to generate the heat necessary to sustain the second stage reaction in this environment. In the 35.8 and 45 at.\% $\mathrm{Al}$ compacts, the synthesis reaction progresses in two distinct stages, as discussed above. In each case, the first reaction stage passes completely through the compact before the second stage begins. In the 54 at.\% Al compact, the two reaction stages

do not appear discrete, as do those in the 35.8 and 45 at.\% Al compacts. Experiments under static vacuum on 35.8 at.\% Al compacts with green densities ranging from $68-78 \%$ of theoretical density showed the same two-stage reaction behavior; therefore green density seems to have little effect on this phenomenon. 
The constituents present in 35.8 at.\% Al specimens reacted in static vacuum and quenched during the first stage correlate well with the results of previous investigations, where quenching of samples was performed at set time intervals. ${ }^{3,4}$ Pure iron and $\mathrm{FeAl}_{3}$ are the major constituents; small amounts of nearly pure aluminum $(95 \mathrm{at} . \% \mathrm{Al})$ are also present. The results for similar specimens that were allowed to react through the second stage are markedly different from those of previous studies. In the earlier investigations, even when the samples were encapsulated in evacuated nickel ${ }^{6}$ or stainless steel ${ }^{7}$ cylinders, the final product was apparently homogeneous. Here, the sample is nonhomogeneous; several constituents are present: stoichiometric $\mathrm{FeAl}\left(50\right.$ at. \% Al), and $\mathrm{Fe}_{3} \mathrm{Al}\left(25\right.$ at. \% $\mathrm{Al}$ ), and small amounts of $\mathrm{FeAl}_{2}$. In powder compacts containing 30 at.\% or less $\mathrm{Al}$, only the first-stage reaction occurs. Electron microprobe analysis on one such sample indicates that this reaction produces free iron and $\mathrm{FeAl}_{3}$; no 95 at. \% Al phase is present. Slight weight gains $(0.02-0.18 \%)$ were recorded in samples synthesized under static vacuum. After synthesis in air, weight gains of 0.8 to $0.9 \%$ were recorded.

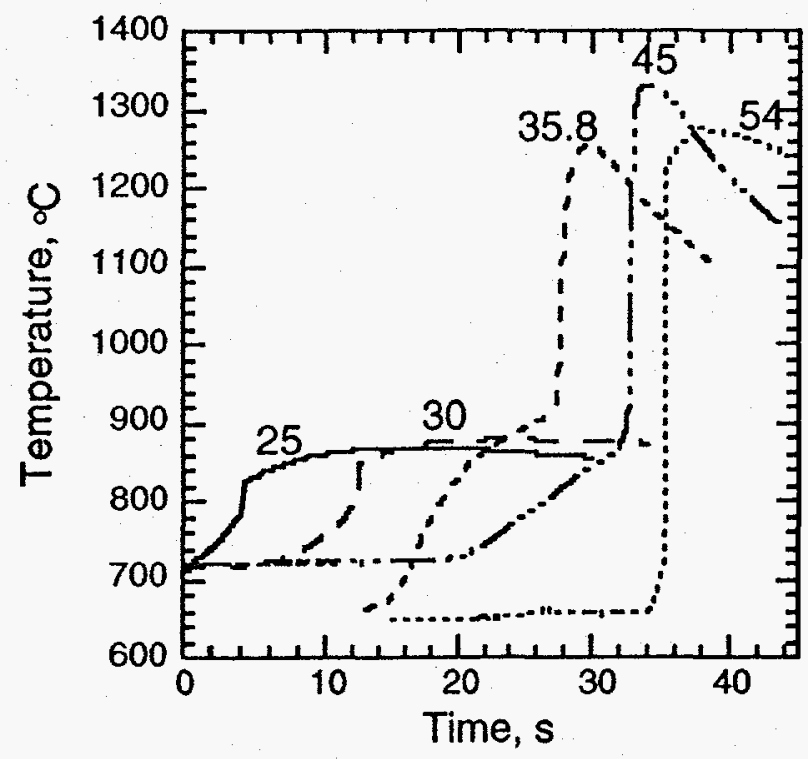

Fig. 2. Pyrometry data from compacts of various

Al compositions, reacted under static vacuum.
Synthesis under dynamic vacuum results in a single-stage (ultimate temperature $\sim 1210^{\circ} \mathrm{C}$ ) reaction for all compositions examined. There is a small weight loss associated with the reaction $(0.6 \%)$, probably due to evaporation of Al during the reaction. No air is available to the reaction, so the temperatures and reaction rates are lower than those observed during the syntheses in air. Electron microprobe analysis of compacts reacted under dynamic vacuum revealed these samples to be virtually homogeneous. In a preliminary study, Miura and Liu ${ }^{17}$ obtained similar results. The fact that the reaction progresses directly from initiation to nearly full homogenization is believed to be due to the slower heat dissipation in the dynamic vacuum. The heat generated from the beginning is not lost quickly, and the reaction progresses immediately to the high-temperature reaction. Likewise, more heat is retained during the reaction under dynamic vacuum and therefore more time is available for diffusion and therefore for homogenization.

The iron powder particle size employed in this study $(45 \mu \mathrm{m})$ is much larger than those used by Rabin, et al. ${ }^{4-6}(8 \mu \mathrm{m})$ and Zhuang et al. ${ }^{7}(7 \mu \mathrm{m})$, but smaller than those used by Lee and German ${ }^{3}(65 \mu \mathrm{m})$. This may partially explain why the two-stage reaction behavior was never reported in this system by these authors.

The differences between powder particle size used in this study and those used in earlier studies are probably significant, since the powder particle size may affect the reaction kinetics and the reaction products by changing the diffusion and heat transfer distances involved. Smaller powder particles have a larger surface-area-to-volume ratio than the larger powder particles, and since the reaction begins at the surface of the iron particles, considerably less diffusion is required for the particles to react fully. In addition to this, the higher Al-content compounds that form at the surface of the iron particles at the beginning of the first reaction stage (the solid-state reaction observed by $\mathrm{DTA}^{4}$ ) probably act as diffusion barriers. For $8-\mu \mathrm{m}$ iron particles, such as those used by Rabin and Wright ${ }^{4-6}$, nearly the whole particle is reacting from the initiation of the reaction, since the surface-to volume ration is so high. In the $45-\mu \mathrm{m}$ iron particles, the relatively large volume of iron surrounded by such a diffusion barrier is unable to react until the heat released raises the compact temperature to around $900^{\circ} \mathrm{C}$, which is enough to allow more diffusion, and thus hasten the formation of $\mathrm{FeAl}_{3}$ (the compound with the highest heat of formation, Table 1), which releases enough heat to ignite the second reaction. 
In summary, the disparities in final reaction products between this and those earlier éxperiments ${ }^{4-8}$ may be due in part to differences in behavior for the two powder particle sizes, the use of different atmospheres, and inadvertent homogenization encouraged by holding the reacted specimens at elevated temperatures $\left(\geq 1000^{\circ} \mathrm{C}\right)$.

Thermodynamic Considerations

Table 3. Enthalpy changes for the observed reactions in this system.

\begin{tabular}{lcc}
\hline Composition & Reactions & $\begin{array}{c}\Delta \mathrm{H}_{\mathrm{f}}, \\
650^{\circ} \mathrm{C} \\
(\mathrm{kJ} / \mathrm{mole})\end{array}$ \\
\hline Fe-40 at.\% Al & $0.6 \mathrm{Fe}+0.4 \mathrm{Al} \rightarrow 0.13 \mathrm{FeAl} 3+0.47 \mathrm{Fe}$ & -9 \\
& $0.6 \mathrm{Fe}+0.4 \mathrm{Al} \rightarrow \mathrm{Fe}_{0.6 \mathrm{Al}_{0.4}}$ & -17 \\
\hline
\end{tabular}

In order to understand the process of reaction sintering in iron aluminides, it is necessary to examine the thermodynamics of the system. The enthalpy changes for the possible reactions based on the electron microprobe results presented here are listed in Table 3. Figure 3 is a plot of enthalpy vs. temperature for the reactions as listed in Table 3. The table and figures were obtained from available thermodynamic data 11-12, using the Kopp-Neumann rule and other estimation techniques 13. The curve for the elemental powders shows jags due to phase changes occurring in iron at various temperatures.

Two hypothetical cases are considered: (1) the adiabatic formation of the appropriate $\mathrm{Fe}_{\mathrm{x}} \mathrm{Al}_{1-\mathrm{x}}$ compound directly from the elemental powders, and (2) the formation of the appropriate $\mathrm{FeAl}_{3}+\mathrm{Fe}$ mixture without heat accumulation followed by the adiabatic formation of the appropriate $\mathrm{Fe}_{\mathbf{x}} \mathrm{Al}_{1-\mathrm{x}}$ compound. Consideration of case (1) reveals that the state of the system changes as indicated by the upper arrow in Fig. 4, with an accompanying rise in temperature of nearly $580^{\circ} \mathrm{C}$. At this point, the product may be nearly molten. In case (2) (Fig. 3, the accompanying temperature rise is only about $250^{\circ} \mathrm{C}$; approximately $50 \%$ of the total enthalpy change is lost. However, in case (1) that rise may be enough to cause the product to melt. The enthalpy loss for the reaction of this powder mixture proceeding as in case (2) is nearly $50 \%$ of the total enthalpy change.

In order to verify the occurrence of the thermite reactions mentioned in the last section (eqns. 1-3), simulations of the reactions as laid out in Table 3 and estimated in Fig. 3 were made using the

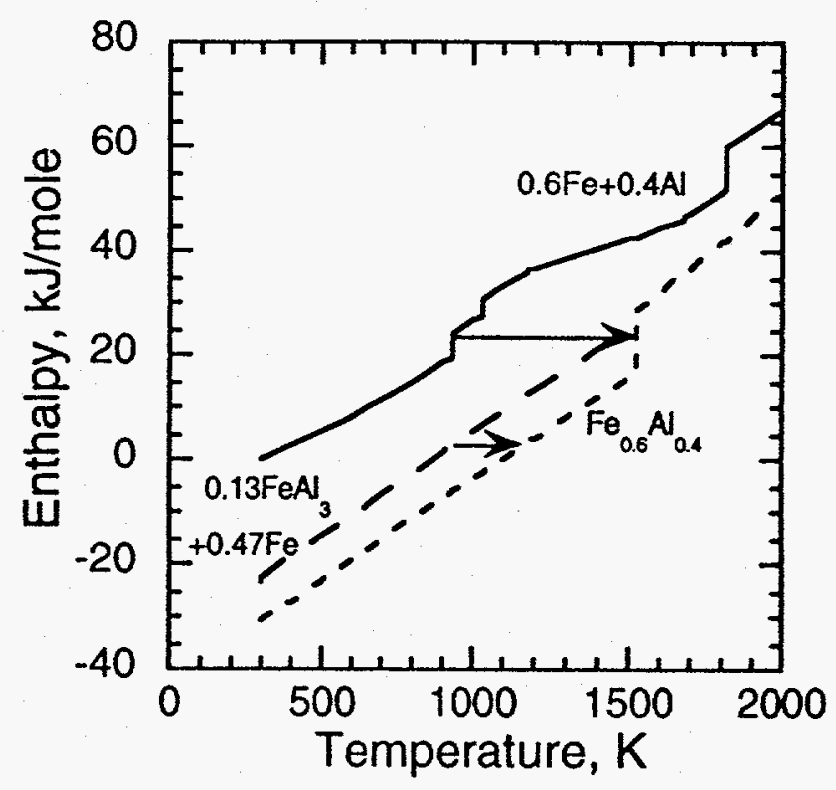

Fig.3. A plot of enthalpy vs temperature for the reactions listed in Table 3. program ThermoCalc(m) 18. From these calculations, at very low mass fractions of oxygen $(<<0.01)$, the adiabatic temperature is about $1325^{\circ} \mathrm{C}$. This is comparable to the ultimate temperatures seen in the experiments under static and dynamic vacuum $\left(1200-1350^{\circ} \mathrm{C}\right)$, where the heat transfer is slow enough to approximate adiabatic conditions. As the fraction of oxygen approaches that observed in the compacts reacted in air (around 0.02 by weighing the entire sample), the calculated adiabatic temperature is about $1450^{\circ} \mathrm{C}$. This is less than that observed for the air reactions $\left(1475^{\circ} \mathrm{C}\right)$, but since the thermite 
reactions are probably taking place only in a thin surface layer-where oxygen is available, the bulk weight gain does not reflect the true oxygen concentration involved in the thermite reactions. The actual oxygen concentrations involved in the surface reaction should be much higher, thus resulting in the higher temperatures observed experimentally. The x-ray diffraction data indicate that the thermite reactions do occur only at the surface in compacts formed from the smaller powder particle size combination and reacted in air. The small amounts of $\mathrm{Al}_{2} \mathrm{O}_{3}$ present in the bulk in specimens formed from the larger powder particle size combination and reacted in air are probably due to air trapped in voids in the green compacts.

\section{CONCLUSIONS}

Several factors affect the progress (duration and extent) of synthesis reactions in $\mathrm{Fe}-\mathrm{Al}$ alloys. Reaction atmosphere, heating rate, and composition all play a role. Ultimately, these factors affect heat accumulation and heat generation, the processes that govern the outcome of the reaction. For example, a two-stage reaction is observed when synthesis occurs under air or static vacuum, while reaction under dynamic vacuum occurs as a single stage. The two-stage reaction is believed to be due to the formation of $\mathrm{FeAl}_{3}$, which acts as a diffusion barrier that must be overcome before the reaction can proceed. Heat transfer and heat generation affect the duration of the first stage of the reaction. During synthesis under dynamic vacuum, the heat generated is retained to a greater extent than during reaction under static vacuum or air; the diffusion barrier is thus overcome very quickly, so the reaction does not occur in separated stages. The occurrence of the thermite reactions during synthesis in air produces additional heat which offsets the heat loss during the reaction. The diffusion barrier is thus overcome more quickly in air than under static vacuum, resulting in an apparently constant reaction rate in air.

\section{Acknowledgments}

The authors are grateful to C. G. McKamey and to Dr. Raju Ramanujan for reviewing the manuscript. This research was sponsored by the Division of Materials Sciences, U.S. Department of Energy, under contract DE-AC05-84OR21400 with Martin Marietta Energy Systems, Inc. and by an appointment to the Oak Ridge National Laboratory Postdoctoral Research Associates Program administered jointly by the Oak Ridge National Laboratory and the Oak Ridge Institute for Science and Education.

\section{REFERENCES}

1. C.G. McKamey, J.H. Devan, P.F. Tortorelli, and V.K. Sikka, J. Mater. Res. 6, 1779 (1991).

2. C.T. Liu and K.S. Kumar, JOM 45 (5), 38 (1993).

3. D.J. Lee and R.M. German, Int. J. Powder Metall. Powder Technol. 21 (12), 9 (1985).

4. B.H. Rabin and R.N. Wright, Metall. Trans. A 22, 277 (1991).

5. B.H. Rabin and R.N. Wright, Metall. Trans. A 23, 35 (1992).

6. B.H. Rabin, R.N. Wright, J.R. Knibloe, R.V. Raman, and S.V. Rale, Mater. Sci. Engng. A153, 706 (1992).

7. L.Z. Zhuang, L. Buekenhout, and J. Duszcyzyk, Scripta Metall. Mater. 30 (7), 909 (1994) .

8. C. Nishimura and C.T. Liu, Acta Metall. Mater. 41 (1), 113 (1993).

9. S. Miura and C. T. Liu, Intermetallics, (1994) (in press).

10. D.L. Joslin, D.S. Easton, C.T. Liu, and S.A. David, J. Mater. Sci. and Engng. (in press).

11. H.D. Fricke in Metals Handbook, 9th ed., vol. 6, (American Society For Metals, Metals Park, OH 1978), pp. 692-704.

12. O. Kubaschewski, C.B. Alcock, and P.J. Spencer, Materials Thermochemistry, 6th. ed., (Pergamon, New York 1993), pp. 163-171.

13. H.C. Yi and J.J. Moore, J. Mater.Sci. 25, 1150 (1990).

14. M. Eslamloo-Grami and Z. A. Munir, J. Mater. Res. 9 (2), 431 (1994).

15. R.N. Wright, B.H. Rabin, and W.H. McFerran, J. Mater. Res. 7 (10), 2736 (1992).

16. H.C. Yi, and J.J. Moore, J. Mater. Sci. 27, 5067 (1992).

17. S. Miura and C.T. Liu, Intermetallics 2, 297 (1994).

18. B. Sundman, B. Jansson, and J.O. Andersson, Calphad 9, 153 (1985). 